\title{
Izipi mehe: cibercaminhos linguísticos e literários para a preservação da cultura Tenetehára
}

\author{
Izipi mehe: linguistic and literary cyberpaths for the \\ preservation of the tenetehára culture
}

\author{
Ricardo Campos Castro ${ }^{1}$ \\ https://orcid.org/0000-0003-3513-1409
}

Pedro Carvalho Guajajara ${ }^{2}$

ORCID: não há

DOI: $10.26512 /$ rbla.v12i1.34846

Recebido em junho/2020 e aceito em setembro/2020

\section{Resumo}

Neste artigo, apresentamos um breve panorama acerca da literatura indígena durante o Romantismo no Brasil. Defendemos a tese de que as contradições desse período foram inevitáveis, constituindo-se apenas em idiossincrasias daquele momento literário. Mais especificamente, sustentamos que, naquele contexto, a voz do indígena brasileiro não se expressaria de outra forma senão por meio da ilegitimidade de sua voz enviesada pela voz do colonizador europeu que atribuía ao indígena sua visão de mundo preconcebida. Outro objetivo deste texto é o de evidenciar um paradoxo hodierno inevitável a respeito da relação que se estabelece entre língua, sistemas linguísticos acadêmicos, literatura e internet. Nessa linha de investigação, apesar de os espaços digitais e os sistemas metalinguísticos acadêmicos de documentação e divulgação das histórias originárias serem alheios à cultura indígena, a coleta e a disponibilização digital de narrativas nos cibercaminhos podem ter como corolário a contribuição com a preservação, documentação e revitalização linguística e literária das culturas indígenas. Diante disso, reproduzimos e apresentamos a análise morfológica da história Tenetehára Izipy mehe Tentehar wazegar haw herur awer (No início, quando os Teneteháras trouxeram a cantoria). Esta história descreve como foram criadas as festas tradicionais do povo Tenetehára. A festa da menina moça, a festa dos rapazes, a festa da colheita, a festa das criancinhas, a festa dos separados, a festa dos pajés e as orações Tenetehára. Segundo esta história originária, essas festas foram trazidas por um antigo Tenetehára que fora levado a outro mundo por seres do céu. Assim, ao voltar para sua própria casa, ele transmite aos seus parentes os rituais aprendidos e apreendidos no outro mundo.

Palavras-chave: Literatura Brasileira. Cibercaminhos. Povos Tupi. Tenetehára.

1 Universidade Estadual de Campinas (UNICAMP), Instituto de Estudos da Linguagem, São Paulo, Brasil. Bolsista de Pós-Doutorado FAPESP. E-mail: ricardorrico@uol.com.br.

2 Universidade Estadual do Maranhão (UEMA), Graduação em Ciências da Linguagem, Maranhão, Brasil. Estudante de Graduação. E-mail: pedro.tentehar190@gmail.com. 


\begin{abstract}
In this article, we present a brief overview of indigenous literature during Romanticism in Brazil. We defend the thesis that the contradictions of this period were inevitable, constituting only idiosyncrasies of that literary moment. More specifically, we maintain that, in that context, the voice of the Brazilian indigenous would not be expressed in any other way than through the illegitimacy of his biased voice by the voice of the European colonizer who attributed the preconceived worldview to the indigenous. Another objective of this text is to highlight an inevitable modern paradox regarding the relationship established between language, academic linguistic systems, literature and the internet. In this line of investigation, despite the fact that digital spaces and academic metalinguistic systems of documentation and dissemination of original stories are alien to indigenous culture, the collection and digital availability of narratives in cyberpaths can be corollary to the contribution to preservation, documentation and linguistic and literary revitalization of indigenous cultures. Therefore, we reproduce and present the morphological analysis of the history Tenetehára Izipy mehe Tentehar wazegar haw herur awer (In the beginning, when the Teneteháras brought the singing). This story describes how the traditional festivals of the Tenetehára people were created. The girl's party, the boys party, the harvest party, the children's party, the separated party, the shamans' party and the Tenetehára prayers. According to this original history, these parties were brought by an ancient Tenetehára who was taken to another world by beings from heaven. Thus, upon returning to his own home, he transmits to his relatives the rituals learned in the other world.
\end{abstract}

Keywords: Brazilian Literature. Internet. Tupí people. Tenetehára.

\title{
Introdução
}

O crítico José Luís Jobim (1997/1998) afirma que os europeus, desde sua chegada ao Brasil, tomaram posse dos indígenas ao atribuir-lhes sua visão de mundo preconcebida. Desse modo, os europeus associaram o comportamento indígena ao estado de Adão, cuja inocência remete ao período anterior às iniquidades da civilização. Nota-se claramente essa atitude dos europeus no seguinte trecho da Carta de Caminha: "homens pardos todos nus sem nenhuma coisa que lhes cobrisse suas vergonhas" (Caminha 1968: 21).

Além disso, de acordo com Jobim (1997/1998), não só os europeus, mas desde seus primórdios, o tema do indígena foi sempre usado pela literatura produzida no Brasil. O autor focaliza o século XIX, em que as características do Romantismo no Brasil se mostram como um dos principais modelos da tematização e apropriação do indígena:

No Brasil que o elegerá como seu herói, entre outras coisas, porque podia ser representado como nativo legítimo do Brasil - aquele que desde sempre aqui viveu, e que lutou heroicamente contra os colonizadores estrangeiros. Nada melhor para um movimento literário nacionalista do que um herói que pode ser apresentado como um produto original de nossa terra (Jobim 1997/1998:35). 
Neste artigo, defendemos a tese de que, apesar de o Romantismo brasileiro assumir uma voz ilegítima do indígena brasileiro, tal percurso fora inescapável, já que

Há um nível de contradição entre a tese da originalidade absoluta, que grassou entre os românticos, e o nacionalismo, vigente naquele período literário. Como conciliar a pretensão à objetividade de uma cultura nacional - que forneceria a identidade a todos que supostamente dela compartilhassem - com a aspiração à subjetividade, à manifestação de uma originalidade autoral livre de influências de outros autores, textos, modelos? (Jobim 1997/1998:45).

Especificamente, sustentamos que, naquele contexto, a voz do indígena brasileiro não se expressaria de outra forma senão por meio da ilegitimidade de sua voz enviesada pela contradição apontada acima por Jobim (1997/1998). Isso porque, diante das condições inerentes ao processo de colonização portuguesa, o cenário brasileiro não permitia outros caminhos. Cabe retomar Antonio Candido ao afirmar que

Historicamente a literatura do período colonial foi algo imposto, inevitavelmente imposto, como o resto do equipamento cultural dos portugueses (...). A nacionalidade brasileira e as suas diversas manifestações espirituais se configuraram mediante processos de imposição e transferência da cultura do conquistador, apesar da contribuição (secundária em literatura) das culturas dominadas, do índio e do africano, esta igualmente importada (Candido 2000:176177).

O outro objetivo deste texto é apresentar mais um paradoxo inevitável a respeito da relação que se estabelece entre língua, povos indígenas e não indígenas, literatura e a internet. Nessa linha de investigação, apesar de os espaços digitais serem alheios à cultura indígena, incluir histórias originárias indígenas no mundo digital tem como consequência a preservação e o revigoramento dessas línguas.

Conforme Giles (2010), a internet surgiu na década de 1960, durante a Guerra Fria, e seus principais objetivos eram: (i) gerar um sistema de comunicação e informação em rede que fosse capaz de resistir a ataques nucleares e (ii) tornar mais dinâmica a troca de informações junto aos centros de colaboração científica. Neste sentido, pode-se ver claramente o quão exterior à cultura indígena é a internet.

Quanto à literatura dos povos indígenas, segundo Bruno e Souza (2016), os nativos, por serem ágrafos, possuíam apenas a tradição oral. Entretanto, a escrita indígena tem se ampliado significativamente a partir do estabelecimento da educação escolar indígena. Por isso, muitas lendas tradicionais têm sido 
documentadas e publicadas em papel pelas mais diversas editoras. Essas narrativas são tanto escritas pelos próprios autores como narradas pelos indígenas e transcritas por linguistas especialistas em tais línguas. Além disso, a inclusão dessas narrativas no mundo digital tem se tornado cada vez mais comum; e as comunidades indígenas têm utilizado os cibercaminhos de várias maneiras. Conforme Guesse (2013), sem contar com recursos financeiros para a publicação de extenso material, os escritores indígenas utilizam amplamente a internet como espaço de propagação de suas reflexões e críticas.

Nesta linha de investigação, o presente artigo apresenta a história Izipy mehe Tentehar wazegar haw herur awer (No início, quando Teneteháras trouxeram a cantoria), inserindo-a no ciberespaço. De acordo com Celeste e Defilippo (2017),

O ciberespaço e a cibercultura estão transformando a Literatura, tanto do ponto de vista estrutural - ao permitir a inserção de novos espaços na narrativa - quanto de sua produção. As facilidades oferecidas pelas novas tecnologias estão possibilitando a formação de novos autores e contribuindo para um maior acesso ao texto literário. Estes cibercaminhos interferem diretamente na Literatura, causando mutações de conceitos e valores cristalizados, ressignificando a relação entre Internet e Literatura (Celeste e Defilippo 2017: 2).

As afirmações das autoras conectam precisamente o caminho percorrido pela literatura indígena até a inclusão digital que o povo autóctone tem conquistado.

$\mathrm{Na}$ próxima seção, apresentaremos brevemente características do Romantismo brasileiro e dos cibercaminhos, com o objetivo de demonstrar que tanto o Romantismo brasileiro quanto os cibercaminhos, apesar de não constituírem a voz autêntica do povo indígena, são caminhos que auxiliam na realização da autonomia e independência desses povos.

Especificamente, defendemos a hipótese de que, tanto no cibercaminhos quanto no Romantismo brasileiro, a voz do indígena pode sim ser notada. São vozes enviesadas ora por autores não indígenas (como no Romantismo), ora por sistemas tecnológicos que são, evidentemente, totalmente externos à cultura indígena (como a internet). Porém, em última instância, essas plataformas colaboram para fortalecer a identidade dos indígenas brasileiros.

O artigo está organizado em quatro seções. Nesta seção, inserimos um panorama geral acerca de todo artigo. Na seção 2, apuramos que as contradições do período do Romantismo no Brasil foram inevitáveis, sendo tão somente o corolário das especificidades daquele momento literário. Além do mais, aventamos a hipótese de que a produção de artigos científicos, além da coleta e disponibilização (inserção no cibercaminhos) digital de narrativas, são modos de contribuir com a preservação, documentação e revitalização linguística e literária das culturas indígenas. $\mathrm{Na}$ seção 3, reproduzimos a história original 
Izipy mehe Tentehar wazegar haw herur awer (No início, quando os Tenetehára trouxeram a cantoria) bem como sua análise morfológica, tendo como objetivos (i) documentar esta importante história originária do povo Guajajára e (ii) revelar características peculiares acerca da estrutura gramatical da língua desse povo, a saber o Tenetehára (Tupí-Guaraní). Finalmente, na seção 4, concluímos com as considerações finais.

Iniciemos, então, com os breves estudos acerca do Romantismo no Brasil por um lado e dos cibercaminhos por outro, bem como da conexão e dos paradoxos que se estabelecem entre essas duas temáticas.

\section{O Romantismo no Brasil e a internet: paradoxos à manifestação da cultura indígena}

Ao se estudar os momentos iniciais da produção literária brasileira, como o período da Literatura de Informação (1500/1600), também denominado Quinhentismo, percebem-se apenas textos de produção lusocêntrica. Assim, "a análise desses textos prova-nos que a história da crítica literária brasileira não reconhece a existência [...] de 'textualidades extraliterárias' ou criações textuais extraeuropeias" (Santos e Wielewicki 2009:338, grifos das autoras). Além do mais, de acordo com as autoras, embora de natureza ágrafa, as culturas indígenas já possuíam naquele momento arte verbal diversificada, porém completamente ignorada pelo colonizador europeu. Ou seja, apesar de sua riqueza, o conhecimento indígena foi o elemento de menor influência na literatura brasileira, que estava nas mãos do colonizador europeu e "submetida a um leitor que não estava disposto a lê-la, a mensagem, ou a poesia indígena, serviu simplesmente como gancho onde pendurar ideias doutrinais" (Santos e Wielewicki 2009:339). Acerca disso, Antonio Candido lembra que a literatura brasileira, em sua formação, é essencialmente europeia, já que dá continuidade à alma da sociedade definida na tradição das metrópoles (Candido 2000).

Ao passar pelo Quinhentismo, Barroco e Arcadismo, quando o auge da produção brasileira é basicamente voltado a uma cópia - para resumir, grosso modo, alguns séculos de produção -, os autores defendem a tese de que a literatura brasileira relacionada ao Romantismo se dava de forma absolutamente original. Isso faz referência ao próprio nacionalismo do período: ao ansiar ser independente de Portugal, seria necessário conquistar tal independência também no plano literário. Assim, seria imperioso produzir uma literatura que fosse majoritariamente brasileira. A esse respeito, Candido lembra que, ao contrário do movimento protagonizado pelos autores românticos, centrados num pretenso indianismo literário, o que foi visto não foi uma "fusão prévia para formar uma literatura, mas modificação do universo de uma literatura já existente" (Candido 2000:165). É possível visualizar, no campo literário daquele período, uma atuação superficial do indígena, que figura como simples 
personagens nas produções dos escritores brasileiros. Por exemplo, em I-JucaPirama de Gonçalves Dias, o indígena reflete o pensamento ocidental de honra, bem típico das novelas de cavalaria medievais. Seguindo essa lógica, a contradição apresentada por Jobim (1997/1998), transcrita na introdução deste artigo, é corroborada por Pagnan:

No caso brasileiro, a questão de ser original foi articulada conforme essas duas direções: o artista individual deveria manifestar seu gênio particular, sua capacidade de criação, e a cultura local um meio de se erigir um novo caminho, um caminho que a diferenciasse da cultura européia. O problema estava em determinar o que seria uma cultura brasileira tendo em vista os mais de três séculos de colonização portuguesa. Em termos literários, o que havia sido produzido até então seria a expressão da alma do brasileiro ou seria antes mera reprodução do que era feito em Portugal e na Europa? (Pagnan 2005:73).

Objetivamente, era impossível desvincular a formação brasileira, consequentemente alterada pela influência portuguesa, do que estava sendo produzido. Por isso, a originalidade almejada era, de certa forma, inviável para não dizer impossível - naquele momento. Contudo, como tal situação se tornou provisoriamente o único meio em que poderia ecoar a voz do indígena - evidentemente objeto de repetidas críticas -, essa voz se torna apenas uma característica do Romantismo no Brasil, sem ser, porém, a voz autêntica dos povos originários.

O Romantismo brasileiro caracteriza-se pelo nacionalismo, e a tematização do indígena não o configura efetivamente. A voz que poderia identificar o indígena não é, de fato, a de um herói europeu, mas sim aquela que apresenta seus próprios heróis culturais. Isso posto, no presente artigo, temos como como objetivo evidenciar a identidade do indígena por meio de uma narrativa advinda dele mesmo, a ser apresentada na próxima seção. Defendemos que o pesquisador que ouve as histórias, documentando-as, realiza um esforço para efetivar a cultura nacional, apesar da evidente contradição de nos valermos de um sistema metalinguístico alheio a essa cultura.

Da forma análoga, em relação aos cibercaminhos, nota-se que a publicação de tais narrativas no espaço virtual leva a contradições, por se usar sistemas totalmente externos à cultura indígena. Especificamente, estamos diante de contrastes bem perceptíveis: (i) sistemas linguísticos e (ii) tecnológicos em benefício de povos indígenas. Paradoxalmente, Munduruku (2008) afirma:

[...] É preciso interpretar. É preciso conhecer. É preciso se tornar conhecido. É preciso escrever - mesmo com tintas do sangue - a história que foi tantas vezes negada. A escrita é uma técnica. É preciso dominar esta técnica com perfeição para poder utilizá-la a favor da gente indígena. Técnica não é negação do que se é. Ao contrário, é afirmação 
de competência. É demonstração de capacidade de transformar a memória em identidade, pois ela reafirma o Ser na medida em que precisa adentrar o universo mítico para dar-se a conhecer o outro. [...] Há um fio tênue entre oralidade e escrita, disso não se duvida. Alguns querem transformar este fio numa ruptura. Prefiro pensar numa complementação. Não se pode achar que a memória não se atualiza. É preciso notar que ela - a memória - está buscando dominar novas tecnologias para se manter viva. A escrita é uma dessas técnicas [...] Pensar a literatura indígena é pensar no movimento que a memória faz para apreender as possibilidades de mover-se num tempo que a nega e nega os povos que a afirmam. A escrita indígena é a afirmação da oralidade (Munduruku 2008).

Guesse (2011, p. 8) afirma que estas declarações de Daniel Munduruku corroboram o conceito de "continuidade" que se estabelece entre tradição oral indígena e literatura. Assim, segundo a autora, Munduruku evidencia a necessidade do fortalecimento da autoria das narrativas. Além do mais, esse fortalecimento autoral tem como corolário o robustecimento da identidade dos grupos indígenas. Finalmente, segundo Guesse, as palavras de Munduruku salientam que o indígena não nega sua tradição oral ao escrever suas histórias. Antes, "ele usa a escrita para manter viva sua oralidade e a partir dela construir sua prática literária, a literatura da floresta" (Guesse 2011:8).

Desse modo, defendemos que a produção de artigos científicos, assim como as coletas de narrativas e sua distribuição nos espaços virtuais, são modos de contribuir com a preservação, documentação e revitalização linguística e literária das culturas indígenas. Também entendemos que os resultados dessas práticas validam a publicação de literatura autóctone brasileira na internet. Isso permite o acesso à literatura indígena - se assim podemos chamar - reduzida por anos a um silenciamento durante o qual os escritores brasileiros não se incomodaram com a realidade das chamadas minorias, mitificando e excluindo ainda mais esse grupo, considerado subalterno e exótico.

Pode-se ainda enfatizar que o acesso ao texto em seu idioma de origem ajuda a combater o silêncio ao qual muitos grupos, sobretudo os indígenas, estiveram fadados ao longo da história literária brasileira. Acerca disso, Regina Dalcastagnè (2013) afirma que:

O silêncio dos grupos marginalizados - entendidos em sentido amplo como todos aqueles que vivenciam uma identidade coletiva que recebe valoração negativa da cultura dominante, sejam definidos por gênero, etnia, cor, orientação sexual, posição nas relações de produção, condição física ou outro critério - é coberto por vozes que se sobrepõem a ele, vozes que buscam falar em nome desses grupos, mas também, embora raramente, pode ser quebrado pela produção literária 
de seus próprios integrantes. É o caso, em particular, das mulheres que há tempos já conquistaram um espaço próprio (embora ainda minoritário) na produção literária (Dalcastagne 2013:42).

No decorrer dos anos, mesmo na produção de editoras dispostas a publicar literatura denominada indígena, o espaço - principalmente em virtude da barreira linguística - obrigava que tal literatura se desse na língua dominante, o português.

A condição do indígena brasileiro, o qual continua submetido à cultura da sociedade à cultura da sociedade nacional brasileiro, não mudou muito no século XXI em relação aos séculos anteriores. Como uma das várias consequências dessa situação muitos indígenas vêm abandonando sua língua materna, circunstância nada desejável nem do ponto de vista étnico e social nem do panorama linguístico e literário. Neste sentido, a produção e divulgação das narrativas pelos próprios indígenas resulta no fortalecimento das culturas autóctones. Como afirma Schøllhammer (2009),

O que encontramos, sim, nesses novos autores, é a vontade ou o projeto de retratar a realidade atual da sociedade brasileira, frequentemente pelos pontos de vista marginais ou periféricos (Schøllhammer 2009:53).

Embora o autor se refira aos novos autores brasileiros contemporâneos, em um quadro específico de análise, cabe destacar que o mesmo nativo indígena, diante da sua condição de subalterno, excluído e silenciado, deve ser considerado também um novo autor. Assim, a produção dessas narrativas como forma de preservação linguístico-cultural é indispensável, já que as línguas, para se manterem vivas, precisam ser continuamente repassadas às gerações mais jovens, sob o risco de desaparecimento.

Conforme Duarte (2016), das 180 línguas faladas no território brasileiro, cerca de 45 a 60 podem desaparecer em um período de 15 anos, considerandose dois principais aspectos: (i) a pressão exercida pelas línguas majoritárias e (ii) o preocupante cenário do número muito reduzido de falantes nativos. A essas questões se soma a redução drástica do território indígena, evidenciado pela "distribuição desigual e descontínua das terras indígenas" (Duarte 2006:5). Rodrigues (1984/1985) apresentava, já na década de 80, levantamento análogo ao de Duarte (2006) ao afirmar que no Brasil existiam cerca de 180 línguas indígenas ativas. Nesse conjunto, as diferenças e semelhanças entre essas línguas revelam procedências comuns e variações advindas do passar do tempo.

Conforme Rodrigues (1955, 1992), Soares e Carvalho (2014), Castro (2017), entre outros, no total das línguas indígenas brasileiras foram identificados até o momento dois grandes troncos linguísticos, o Tupí e o Macro-Jê, além de outras 19 famílias cujos percentuais de afinidade não bastam para que se possa 
reuní-las em troncos. Há ainda muito que se desvendar e pesquisar acerca das culturas indígena, e a literatura se mostra um caminho de expressiva relevância. Ao mesmo tempo, se essa manutenção se realiza aliada a possibilidades ofertadas pelo espaço virtual, a decorrida imposição e transferência da cultura do colonizador (como apontada por Candido (2000)) poderá ser substituída pela voz do próprio indígena, valendo-se de uma autoridade até então escassa ou ausente.

A respeito da redução das línguas indígenas no Brasil, pode-se vislumbrar uma luz no fim do túnel por intermédio do reconhecimento dessas línguas, ainda que tardiamente. Oficialmente, essa autenticação se deu na Constituição de 1988, no capítulo "Dos índios", que contém os artigos 231 e 232. Esses artigos reconhecem "sua organização social, costumes, línguas, crenças e tradições, e os direitos originários sobre as terras que tradicionalmente ocupam" (Brasil 1988).

A Constituição de 1988 deu origem às escolas indígenas bilíngues atuais. De acordo com Souza (2001), já havia escolas indígenas no Brasil antes dessa data; entretanto, seguia-se o currículo nacional brasileiro de educação, o que não proporcionava aos alunos indígenas o conhecimento de sua cultura local. Para Santos e Wielewicki (2009),

A criação de uma escola bilíngue entre as comunidades indígenas abriu espaço para um novo texto sobre o índio e para o índio. Apesar de em sua maioria serem de cunho antropológico e educacional (registros e transcrições de histórias contadas pelos índios e transformados em material didático), muitos livros sobre a cultura indígena vêm sendo publicados e usados nos últimos anos nas centenas de escolas indígenas espalhadas pelo Brasil. As estratégias na criação desses livros são pensadas de acordo com a percepção política e consciência histórica de cada povo. Assim, histórias do mundo moldadas pelos índios vêm sendo documentadas em diferentes publicações, algumas delas de autoria dos próprios índios (Santos e Wielewicki 2009:339).

No que se refere à utilização da internet pelos povos indígenas, assim como a conexão estabelecida entre internet e literatura, é particularmente importante o que afirma Bueno (2013):

Muitos povos indígenas têm usado a rede para atingir um público grande, dentro e fora do país. Os recursos on line são usados para romper o isolamento em que muitas comunidades vivem, e também para vencer a barreira da falta de espaço que esses povos têm nas mídias tradicionais. "A Internet possibilita aos indígenas divulgar suas culturas e potencialidades de forma mais independente e autônoma, se fazendo conhecer e dialogando diretamente com a população nacional", aponta Thiago Cavalcante, historiador e pesquisador do 
Laboratório de Arqueologia, Etnologia e Etno-História (Etnolab) da Universidade Federal de Grande Dourados (UFGD) e do grupo de pesquisas do Centro de Estudos Indígenas Miguel A. Menendéz (Ceiman) da Unesp de Araraquara (SP).

Nessa perpectiva, importantes conquistas têm ocorrido, como publicações de narrativas em papel, tais como o livro de Mimápoty (2011), Com a Noite Veio o Sono. Essa autora indígena, pertencente à etnia Maraguá, narra a criação da noite. Apesar de ser narrada apenas em português, a lenda foi contada pela própria indígena e se constitui em um importante avanço relativo à documentação e preservação da sabedoria tradicional indígena. De fato, consoante Resende (2008), é urgente que toda nova classe de autores descriminados e marginalizados seja capaz de eliminar os mediadores que roubam suas vozes, logo

Na literatura, o sentido de urgência, de presentificação, se evidencia por atitudes, como a decisão de intervenção imediata de novos autores presentes na universo da produção literária, escritores moradores da periferia ou segregados da sociedade, como os presos, que eliminaram mediadores na construção de narrativas, com novas subjetividades fazendo-se definitivamente donas das próprias vozes (Resende 2008:27-28, grifo da autora).

Outra obra que apresenta lenda semelhante à de Mimápoty (2011) é a de Duarte et al (2018), Castro (2018) e Castro \& Fernandez (2019), A criação da Noite. Essa é uma história bilíngue coletada por linguistas e com a assessoria de contadores de narrativas indígenas falantes da língua Tenetehára, pertencente à família linguística Tupí-Guaraní. Cabe destacar que a publicação de A criação da Noite passa pela mediação de não indígenas, prática ainda comum atualmente.

A seguir, reproduzimos a história original Izipy mehe Tentehar wazegar haw herur awer (No início, como os Tenetehára trouxeram a cantoria), bem como sua análise morfológica, cujo intuito é revelar características peculiares acerca da estrutura gramatical da língua Tenetehára (Tupí-Guaraní).

\section{Uma história originária do povo Tenetehára}

A narrativa que apresentamos neste trabalho é um texto narrado e escrito por um indígena e analisado morfologicamente e revisado por um linguista. Tanto o indígena quanto o linguista são os autores do presente artigo. A história descreve como foram criadas as festas tradicionais do povo Tenetehára. A festa da menina moça, a festa dos rapazes, a festa da colheita, a festa das criancinhas, a festa dos separados, a festa dos pajés e as orações Tenetehára. Segundo esta história originária, essas festas foram trazidas por um antigo Tenetehára que 
fora levado a outro mundo por seres do céu. Assim, ao voltar para sua própria casa, ele transmite aos seus parentes os rituais aprendidos no outro mundo.

Percebe-se que as narrativas orais dos diversos povos indígenas são um reflexo da sua própria realidade, em que seres humanos, deuses e animais convivem em um determinado espaço variegado e fluido. $\mathrm{O}$ pensamento indígena emerge de uma relação harmoniosa com a natureza que os rodeia, e que se reflete no emprego das palavras e seus respectivos significados. Nesse sentido, as narrativas permitem observar a forma peculiar e idiossincrática das culturas indígenas em conceber o mundo. Passemos, então, à narrativa, bem como a sua análise morfológica.

\section{Izipy mehe Tentehar wazegar haw herur awer}

$\begin{array}{lllll}\text { izypy mehe } & \text { wa-zegar } & \text { haw } & \text { h-erur } & \text { (h)aw(kw)er } \\ \text { começoquando } & \text { PL-cantar } & \text { NOML } & \text { 3-trazer } & \text { NOML-PAS }\end{array}$

No início, quando os Tentehar trouxeram a cantoria"

01) Mukuz awa wà uzeme'kar zekaipo oho a'e wà.

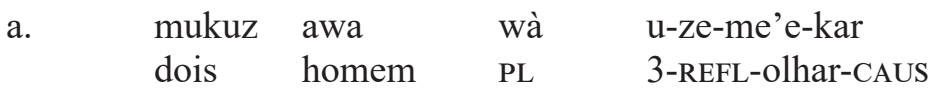

b. ze-k(wehe)-aipo o-ho a'e wà

N.NAT-faz.tempo-DUB 3 -ir $3 \quad$ PL

"(Há muito tempo, ouviu-se dizer), dois homens (se encontraram e)

foram caçar juntos"

02) Wiràmiri uzuka oho wà.

$\begin{array}{llll}\text { wiràmiri } & \text { u-zuka } & \text { o-ho } & \text { wà } \\ \text { pássaro } & \text { 3-matar } & 3 \text {-ir } & \text { PL } \\ \text { "Eles foram } & \text { matar pássaros" }\end{array}$

3 Abreviaturas utilizadas: ASP aspecto; AUM aumentativo; C prefixo que indica contiguidade ao complemento; CAUS causativo; CERT modalidade epistêmica de certeza; CHNG partícula que indica uma mudança de estado ou asserção (change); COM morfema comitativo; DBT modalidade epistêmica de dúvida; DIM diminutivo; ENF marcador de ênfase; EXCL exclusivo; FUT futuro; G genérico; GER gerúndio; GNDL partícula de gênero (genderlect); IMP imperativo; N.AT partícula evidencial que indica uma situação não atestada pelo falante); NC prefixo que indica não contiguidade ao complemento; NEG negação; MNT partícula que indica manutenção de estado ou asserção; NOML nominalizador; PASS passado; PL plural; POSS posse; PSB modalidade eventiva de possibilidade e permissão; QU marcador de pergunta; RED reduplicação; REFL unidade gramatical reflexiva; SG singular; TRANSL caso translativo. 
03) Uzapoapo zekaipo tukaz ma'e 'ywa'yw rehe wà.

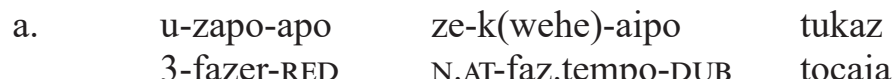

b. ma'e-'ywa-'yw r-ehe wà

coisa-pé.RED C-em PL

"Eles fizeram uma tocaia em árvores frutíferas (pé de coisas).

04) Muite werota'i izuwi wà.

muite werota'i i-zuwi wà

longe um.pouco NC-de PL

"Ficaram um pouco distantes um do outro"

05) Amo itukaz rehe nàpytà'i kwaw wiràmiri a'e wà.

amo i-tukaz r-ehe na-pità'i-kwaw wiràmiri a'e wà

outro NC-tocaia C-em NEG-um-NEG pássaro 3 PL

"Na tocaia de um deles, havia muitos pássaros (não era um)"

06) Tuweharupi uzuka katetea'u wiràmiri a'e pe.

tuweharupi u-zuka katete-a'u wiràmiri a'e pe todos.os.dias 3-matar ENF-AUM pássaro $3 \mathrm{em}$ "Todos os dias, ele matava muitos pássaros lá"

07) Tywyr tukaz rehe nahetatete kwaw wiràmiri izupe a'e pe.

a. t-ywyr tukaz r-ehe na-h-eta-tete-kwaw

3-irmão.mais.novo tocaia C-em NEG-3-ter-ENF-NEG

b. wiràmiri i-zupe a'e pe

pássaro 3-para 3 em

"Na tocaia do irmão mais novo, não havia muitos pássaros (lá)"

08) Amo 'ar mehe katu izekyty'ar zekaipo tywyr oho hapuz naw pe.

a. amo 'ar mehe katu i-zekyty'ar ze-k(wehe)-aipo

algum dia quando ENF 3-passear N.AT-faz.tempo-DUB

b. t-ywyr o-ho h-apuz naw ø-pe

3-irmão.mais.novo 3-ir NC-casa NOM C-em

"Certo dia, o irmão mais novo foi passear na casa do irmão mais velho" 
09) Wexak zekaipo wyky'yr ima'e zapoapopyrer tetea'u a'e pe.

a. w-exak ze-k(wehe)-aipo w-yky'yr i-ma'e 3-ver N.AT-faz.tempo-DUB 3-irmão.mais.velho 3-coisa

b. zapo-apo-pyr-(kw)er tete-a'u a'e pe

fazer-RED-NOM-PASS ENF-ENF 3 em

"Ele viu que o irmão mais velho já havia feito várias plumagens (coisas dos pássaros)"

10) I'i zekaipo wyky'yr pe: ikatuahy tuwe aipo nerukaz aipo ne pa.

$\begin{array}{llll}\text { i-’i } & \text { ze-k(wehe)-aipo } & \text { w-yky’yr } & \text { ø-pe } \\ \text { 3-dizer } & \text { N.AT-faz.tempo- DUB } & \text { 3-irmão.mais.novo } & \text { C-em }\end{array}$

i-katu-ahy tuwe aipo ne=r-ukaz aipo ne pa 3-bom-ENF ENF DUB 2SG-C-tocaia DUB 2SG GNDL

"Então, ele disse ao seu irmão: essa sua tocaia é boa mesmo"

11) Naheta katu kwaw wiràmiri a'e pe ihe ty i'i izupe.

a. na-h-eta-katu-kwaw wiràmiri a'e pe ihe ty NEG-3-ter-bom-NEG pássaro 3 lá C-em GNDL

b. i-'i i-zupe

3-dizer NC-para

"Na minha (tocaia) não dá muito pássaro, disse ele"

12) Emururapi'ez nerukaz hewe nehe rihi no ty? i'i wyky' yr pe:

a. e-mururapi'ez ne=r-ukaz h-ewe nehe rihi no ty 2.IMP.emprestar $2=\mathrm{C}$-tocaia 3 -para FUT $\quad$ PSB MNT GNDL

b. i-’i w-yky'yr $\quad$-pe

3-dizer 3- irmão mais velho c-em

"Me empresta sua tocaia? Ele disse ao seu irmão mais velho"

13) Kwa! Napuner kwaw imono haw newe ty, i’i tyky'yr izupe

a. kwa! n-apuner-kwaw i-mono-haw ne=ø-we ty, ah NEG-poder-NEG 3-dar-NOML $2 \mathrm{sG}=\mathrm{C}$-para $\quad$ GNDL

b. i-'i t-yky'yr i-zupe

3-dizer G-irmão.mais.velho 3-para

"Ah! Não posso te emprestar, disse o irmão mais velho a ele" 
14) Okwa! Emururapi'ez ihewe ty tazuka kutu wiràmiri hema'e izapopyràm rehe ihe no ty, ta'e izapopaw ete ne ma'e ne wà ri'i xe.

a. okwa e-mururapi'ez ihe=ø-we ty ta-zuka-kutu oh 2.IMP-emprestar 1sG-C-para GNDL 1sG-matar-poder

b. wiràmiri he=ø-ma'e i-zapo-pyr-(r)àm r-ehe ihe no ty, pássaro $\quad 1=\mathrm{C}$-coisa 3-fazer-NOML-FUT $\mathrm{C}$-em $1 \mathrm{SG} \quad \mathrm{MNT}$ GNDL

c. ta'e i-zapo-paw ete ne ma'e ne wà ri'i xe porque 3-fazer-tudo ENF 2SG coisa 2SG PL CERT GNDL "Oh! Empreste para mim, deixe eu poder matar os pássaros na minha feitura delas (das minhas coisas, minhas plumagens), já que as suas coisas (plumagens) estão quase todas feitas"

15) Kwa namono wer kwaw zepe herukaz rehe newe ty, ta'e reta amo ma'e a'e pe wà xe.

a. kwa n-amono-wer-kwaw zepe

EXCL NEG-dar-querer-NEG infelizmente

b. he=r-ukaz r-ehe ne=ø-we ty, $1=$ C-tocaia 3 -em $2 \mathrm{sG}=\mathrm{C}$-para $\quad$ GNDL

c. ta'e h-eta amo ma'e a'e ø-pe wà xe porque 3-ter outro coisa 3 C-em PL GNDL "Eu não iria emprestar minha tocaia a você, pois tem umas coisas lá"

16) Nàry’ym erexiroxiro xi wanupe neà.

nàry' $y m$ ere-xiro-xiro $\quad \mathrm{xi} \quad \mathrm{wa}=$ n-upe neà talvez 2-mexer-RED 1PL 3PL-C-com 2SG

"Talvez você vá mexer com eles"

17) Naxixiro kwaw wanupe ihe ty.

$\begin{array}{llll}\text { na-xixiro-kwaw } & \text { wa }=\text { n-upe } & \text { ihe } & \text { ty. } \\ \text { NEG-mexer-NEG } & 3 \mathrm{PL}=\mathrm{C}-\mathrm{COM} & 1 \mathrm{SG} & \text { GNDL }\end{array}$

"Eu também não vou mexer com eles"

18) i’i t-yky'yr i-zupe:

i-’i t-yky'yr i-zupe

3-dizer 3-irmão.mais.velho NC-para

"O irmão mais velho disse para ele (o irmão mais novo)" 
19) Te'e ere ty?

te'e ere ty

verdade 2SG GNDL

"É verdade o que você está dizendo?"

(20) Aze nazewe xe, a'e ma'e wà , aze 'ur putar wà, uzywytutete tary, a'e uhem 'ur putar wà nehe.

a. aze nezewe xe a'e ma'e wà

se assim GNDL 3 coisas PL

b. aze 'ur-putar wà u-zywytu-tete-tary,

se vir-FUT PL 3-ventar-ENF-começar

c. a'e u-hem 'ur putar wà nehe

3 3-chegar vir FUT PL FUT

"Sendo assim, essas coisas, quando estão vindo, começa a ventar muito, são eles chegando"

21) Exiroxiro zo wanupe nehe ty, ma'eputyr tykwer zogatu umui'e putar a'e wà ty a'ere oho putar wà kury.

e-xiro-xiro zo wa=n-upe nehe ty,

2IMP.mexer-RED Só 3PL $=\mathrm{C}-\mathrm{em} \quad$ FUT $\quad$ GNDL

$\begin{array}{llllll}\text { ma'eputyr } & \text { ty-kwer } & \text { zo } & \text { gatu } & \text { u-mu-i'e } & \text { putar } \\ \text { flor } & \text { líquido-PaSs } & \text { só } & \text { ENF } & 3 \text {-CAUS-espremer } & \text { FUT }\end{array}$

a'e wà ty a'e re o-ho putar wà kury

3 PL GNDL 3 depois 3-IR FUT PL CHNG

"Não mexa com eles, eles só vão espremer o néctar das flores; depois

disso, vão embora"

22) Amonopi'ez aipo newe pa.

a-mo-no-pi'ez aipo ne=ø-we pa

1-CAUS-ir-ASP DUB 2SG-C-para GNDL

"Eu te empresto"

23) A'e ku'em re oho zekaipo wyky'ym hukaz pupe kury.

a. a'e ku'em re o-ho ze-k(wehe)-aipo

3 dia depois 3-ir N.AT-faz.tempo-dúvida 
b. w-yky'ym h-ukaz ø-pupe kury

3-irmão.mais.velho Poss-tocaia C-dentro CHNG

"No outro dia, cedo, ele (o irmão mais novo) foi à tocaia do irmão mais velho dele"

24) Uzepyrog wiràmiri wazuka haw rehe a'e kury.

a. u-zepyrog wiràmiri wa-zuka-haw

3-REFL-pisar pássaro PL-matar-NOML

b. r-ehe a'e kury

C-em 3 CHNG

"Então, ele (o irmão mais novo) começou a matar os pássaros"

25) Aze zekaipo kwarahy ur zapyte katete, izywytu zekaipo nery'ymete, a'e zekaipo a'e zawar ywatehar wà.

a. aze ze-k(wehe)-aipo kwarahy u-(u)r zapyte-katete, se N.AT-faz.tempo-dúvida dia 3-vir parte.alta-ENF

b. i-zywytu ze-k(wehe)-aipo nery'ymete

3-vento N.AT-faz.tempo-dúvida de.repente

c. a'e ze-k(wehe)-aipo a'e zawar ywate-har wà

3 N.AT-faz.tempo-dúvida 3 cachorro cima-NOML PL

"Quando deu meio dia em ponto, de repente, começou a ventar muito, eram os seres sobrenaturais (cachorros do céu)"

26) Wapyk zekaipo ta'yuhu katu oho tukaz huwakete.

a. w-apyk ze-k(wehe)-aipo t-a'yr-uhu katu

3-sentar N.AT-faz.tempo-dúvida G-filhote-AUM ENF

b. o-ho t-ukaz h-uwake-(e)te

3-ir G-tocaia 3-perto-ENF

"Um dos seres de porte médio sentou bem perto da tocaia"

27) Ume'egatu zekaipo tukaz rehe.

u-me'e-gatu ze-k(wehe)-aipo t-ukaz r-ehe

3-olhar-ENF N.AT-faz.tempo-dúvida G-tocaia 3-em

"Ele olhava fixamente para a tocaia"

28) Ta'e zekaipo wetun hekwen xe.

ta'e ze-k(wehe)-aipo w-etun h-ekwen xe

então N.AT-faz.tempo-dúvida 3-cheirar 3-cheiroso GNDL

"Então, ele (um dos seres sobrenaturais) sentiu o cheiro dele do irmão mais novo" 
29) Uzepyrog zekaipo zawar ma'eputyr imui'e'ehaw rehe wà.

a. u-ze-pyrog ze-k(wehe)-aipo

3-REFL-pisar N.AT-faz.tempo-dúvida

b. zawar ma'eputyr i-mu-i'e'e-haw r-ehe wà cachorro flor 3-CAUS-expremer-NOML C-em PL "Então, os cachorros do céu começaram a colher o néctar"

30) Izypy mehe, ukyze wanuwi.

izypy mehe, u-kyze wa=n-uwi

começo quando 3-temer $3 \mathrm{PL}=\mathrm{C}$-de

"No início, ele (o irmão mais novo) sentiu medo deles"

31) Ume'egatu zekaipo wanehe, uma'enukaw zekaipo wyky'yr ze'egwer rehe uzeupe.

a. u-me'e-gatu ze-k(wehe)-aipo wa=n-ehe

3-olhar-ENF $\quad$ N.AT-faz.tempo-dúvida $3 \mathrm{PL}=\mathrm{C}$-para

b. u-ma'enukaw ze-k(wehe)-aipo w-yky'yr

3-pensar N.AT-faz.tempo-dúvida 3-irmão.mais.velho

c. ze'eg-wer r-ehe u-ze-upe

falar-PASS C-em 3-REFL-para

"Ele (o irmão mais novo) olhava para eles fixamente, então, ele se lembrou do que o irmão dele havia dito a ele"

32) Agwer aipo ma'e hexakpyr wà pa, i'i uzepiamiapo pà.

$\begin{array}{llllll}\text { agwer } & \text { aipo } & \text { ma'e } & \text { h-exak-pyr } & \text { wà } & \text { pa } \\ \text { aqueles.tipos } & \text { dúvida } & \text { coisa } & \text { 3-ver-NOML } & \text { PL } & \text { GNDL }\end{array}$

i’i u-zepy'amiapo pà

3-dizer 3-pensar GER

"Então, ele (o irmão mais novo) pensou consigo mesmo: esses devem ser os seres (coisas) que o meu irmão viu"

33) Uzepyrog zekaipo uzeputupyk haw wanehe, ta'e zekaipo umukuhem paw wiràmiri uzuwi xe.

a. u-ze-pyrog ze-k(wehe)-aipo u-ze-putupyk-(h)aw wa=n-ehe

3-REFL-pisar N.AT-faz.tempo-dúvida 3-REFL-chatear-NOML $\quad \mathrm{PL}=\mathrm{C}$-com

b. ta'e ze-k(wehe)-aipo u-mu-kuhem paw

então N.AT-faz.tempo-dúvida 3-CAUs-espantar.se todos 
c. wiràmiri u-zuwi xe

pássaro C-de GNDL

"Ele (o irmão mais novo) começou a se chatear com eles (os seres sobrenaturais), porque eles tinham espantado todos os pássaros dele"

34) Uwagaw ipy zekaipo u'yw wanehe, nomomor kwaw imono wanupe rihi.

a. u-wagaw i-py ze-k(wehe)-aipo u'yw wa=n-ehe

3-tentar 3-ponta N.AT-faz.tempo-dúvida flecha $\quad \mathrm{PL}=\mathrm{C}$-em

b. n-omomor-kwaw i-mono wa=n-upe rihi

NEG-disparar-NEG 3-mandar $\quad \mathrm{PL}=\mathrm{C}$-em $\quad \mathrm{PSB}$

"Ele (o irmão mais novo) apontou a ponta da flecha neles, mas ela não disparou"

35) Uri’ahy zekaipo izupehar kury.

u-(u)ri'-ahy ze-k(wehe)-aipo i-zupe-har kury

3-vir-ENF N.AT-faz.tempo-dúvida NC-para-NOM CHNG

"A tentação (de atirar a flecha) foi grande"

36) Ume'egatu zekaipo amo ta'yruhu katu hehe.

u-me'e-gatu ze-k(wehe)-aipo

3-olhar-ENF N.AT-faz.tempo-dúvida

amo t-a'yr-uhu katu h-ehe

outro G-filhote-AUM ENF NC-para

"Um dos seres de porte médio estava olhando bem para ela (a tocaia)"

37) Wagaw u'yw a'e rehe, umutyk zekaipo wyrapar kury.

a. w-agaw u'yw a'e r-ehe,

3-tentar flecha $3 \quad$ C-em

b. u-mutyk ze-k(wehe)-aipo wyrapar kury

3-arrastar N.AT-faz.tempo-dúvida arco CHNG

"Então, ele (o irmão mais novo) apontou a flecha pra esse ser, e então puxou o arco"

38) Imomor pà u'yw hehe kury.

i-momor pà u'yw h-ehe kury

3-disparar GER flecha NC-em CHNG

"Então, ele disparou a flecha" 
39) Upynykwaw tuwe zekaipo amo zawar u'uru'yw uzuwà wà, na'arew ahy.

a. u-pynykw-(h)aw tuwe ze-k(wehe)-aipo amo 3-dançar-NOM ENF N.AT-faz.tempo-dúvida outro

b. zawar u-'ur u'yw u-zuwà wà, na'arew-ahy cachorros 3-vir flecha 3-flechar PL rapidamente-ENF "Os outros cachorros vieram ao encontro da flecha rapidamente"

40) Upehe'àg zekaipo tukaz hehe wà, izuka pà wà.

a. u-pehe'àg ze-k(wehe)-aipo tukaz h-ehe wà 3-partir N.AT-faz.tempo-dúvida tocaia NC-em PL

b. i-zuka pà wà

3-matar GER PL

"Eles partiram a tocaia ao meio, matando-o"

41) Weraha wekohaw pe wà.

w-era-ha w-eko-haw ø-pe wà

3-COM-ir 3-estar-NOML C-para PL

"E eles o levaram para a morada deles"

42) Tyky'yr oho zekaipo hapuz me, hehe puranu pà:

a. t-yky'yr o-ho ze-k(wehe)-aipo h-apuz

G-irmão.mais.velho 3-ir N.AT-faz.tempo-dúvida NC-casa

b. ø-me h-ehe puranu pà

C-em NC-por perguntar GER

"O irmão mais velho dele foi à casa dele perguntar por ele"

(43) -Uhem Maira'i uzura'a? i'i uiwyraty pe

a. u-hem Maira'i u-zur ra'a i-'i

3-chegar 3-vir DUB GNDL 3-dizer

b. u-iwyraty $\varnothing-p e$

Poss-cunhada C-para

"-O Maira'i chegou? Ele (o irmão mais velho) perguntou para a cunhada"

44) Tyky'yr ipy'a ukwaw tuwe ma'e uzeapo ma'e kwer izupe a'e.

t-yky'yr i-py'a u-kwaw tuwe ma'e

G-irmão.mais.velho 3-fígado 3-saber ENF coisa 
u-ze-apo-ma'e-kwer i-zupe a'e

3-REFL-fazer-NOML-PASS NC-com 3

"O irmão dele (do irmão mais novo) já sabia aquilo que havia acontecido com ele (o irmão mais novo"

45) -Nan, nuhemkwaw ur rihi ' $y$.

$\begin{array}{lllll}\text { nan, } & \text { n-u-hem-kwaw } & \mathrm{u}(\mathrm{u}) \text {-r } & \text { rihi } & \text { ' } \mathrm{y} \\ \text { não } & \text { NEG-3-chegar-NEG } & \text { 3-vir } & \text { PSB } & \text { GNDL }\end{array}$

"Não, ele não chegou, disse ela (a cunhada do irmão mais velho)"

46) Aha putar haikwer romo i'i zekaipo izupe.

a. a-ha putar h-aikwer r-omo i-'i

1SG-ir FUT 3-atrás 3-TRANSL 3-dizer

b. ze-k(wehe)-aipo i-zupe

N.AT-faz.tempo-dúvida NC-para

"Eu vou atrás dele, disse (o irmão mais velho) para ela"

47) Oho zekaipo haikwer romo, muitewiwe wexak zekaipo tukaz pegwer a'e.

a. o-ho ze-k(wehe)-aipo h-aikwer r-omo,

3-ir N.AT-faz.tempo-dúvida 3-atrás 3-TRANSL

b. muite w-iwe w-exak ze-k(wehe)-aipo t-ukaz

longe 3-avistar 3-ver N.AT-faz.tempo-dúvida G-tocaia

c. peg-(k)wer

pedaço-PASS

"Ele (o irmão mais velho) foi pelo caminho por onde ele (o irmão mais novo) tinha ido; de longe, ele avistou os pedaços da tocaia"

48) -Ty! A'e zepe tuwe akwez newe ihe ri'i xe.

a. ty a'e zepe tuwe akwez ne=ø-we

GNDL 3 contrário.ao.fato $\mathrm{ENF}$ aquele $2 \mathrm{SG}=\mathrm{C}-$ para

b. ihe ri'i xe

1SG CERT GNDL

"Rapaz! Eu te falei"

49) Ne xixirog wer wanupe ri'i ty i'i izeupe.

a. ne xixirog-wer wa=n-upe ri'i ty

$2 \mathrm{SG}$ PASS $3 \mathrm{PL}=\mathrm{C}-\mathrm{em} \quad \mathrm{CERT} \quad \mathrm{GNDL}$ 
i-'i i-ze-upe

3-dizer NC-REFL-para

"Você não devia ter mexido com eles, disse ele (o irmão mais velho)

para si mesmo"

50) Wekar xi zekaipo a'e pe, nuwexak kwaw heraha awer, wekar we xi zekaipo a'e pe.

a. w-ekar xi ze-k(wehe)-aipo a'e pe

3-procurar ali N.AT-faz.tempo-dúvida 3 em

b. n-u-wexak-(k)waw h-era-ha-aw(kw)er

NEG-3-ver-NEG 3-COM-ir-NOML-PASS

c. w-ekar we xi ze-k(wehe)-aipo a'e pe

3-ver novamente ali N.AT-faz.tempo-dúvida 3 em

"Ele (o irmão mais velho) procurou ali, não viu por onde eles (os cachorros do céu) o tinham carregado, e procurou novamente lá"

51) Wexak zekaipo amo huwykwer ka'a rehe.

a. w-exak ze-k(wehe)-aipo

3-ver N.AT-faz.tempo-dúvida

b. amo h-uwy-kwer ka'a r-ehe

outro 3-sangue-PASs mato 3-em

"Ele procurou novamente, então ele viu um pingo de sangue numa folha de árvore"

52) Oho zekaipo hurkwer tyktykyr awer hupi a'e, izahyk zekaipo oho ya'o 'ykwar rehe.

a. o-ho ze-k(wehe)-aipo hury-(kw)er tyky-tykyr

3-ir N.AT-faz.tempo-dúvida sangue-PASs pingo-RED

b. (h)aw(kw)er h-upi a'e

NOML-PASS NC-por 3

c. i-zahyk ze-k(wehe)-aipo o-ho

3-final N.AT-faz.tempo-dúvida 3-ir

d. ya'o 'y-kwar r-ehe

saúva POss-buraco C-em

"O irmão mais velho foi seguindo os pingos de sangue, e os pingos de sangue pararam no buraco de saúva (no final)" 
53) A'e pe zekaipo a'e ma'e wane kohaw ipi’arà.

a'e pe ze-k(wehe)-aipo a'e ma'e

3 em N.AT-faz.tempo-dúvida 3 coisa

wa $=$ n-eko-haw i-pi'arà

$\mathrm{PL}=\mathrm{C}$-estar-NOML 3-caminho

"Lá era a entrada (o caminho) da morada deles"

54) Uhewikàz xi zekaipo tyky'yr a'e ya'o ikwar a'e, nuhem kwaw zekaipo a'e wanekohaw pe.

a. u-hewikàz-xi ze-k(wehe)-aipo

3-cavar-PASS N.AT-faz.tempo-dúvida

b. t-yky'yr a'e ya'o i-kwar a'e,

G-irmão.mais.velho 3 saúva NC-buraco 3

c. n-u-hem-kwaw ze-k(wehe)-aipo

NEG-3-chegar-NEG N.AT-faz.tempo-dúvida

d. a'e wa=n-eko-haw ø-pe

3 3PL-C-ser-NOML C-em

"O irmão dele cavou o buraco da saúva, mas ele (o irmão mais velho) não chegou à aldeia deles"

55) Amo ar mehe katu uzeapo zekaipo tezuhu romo,

a. amo ar mehe katu u-ze-apo ze-k(wehe)-aipo

algum dia quando ENF 3-REFL-fazer N.AT-faz.tempo-dúvida

b. tez-uhu r-omo

lagarto-AUM C-TRANSL

"Então, certo dia, ele se transformou em um lagarto"

56) Nawizeahykwaw zeikaipo heixe haw a'e ya'o ikwa rupi.

a. n-awize-ahy-kwaw ze-k(wehe)-aipo

NEG-caber-ENF-NEG N.AT-faz.tempo-dúvida

b. h-eixe-haw a'e ya'o i-kwa r-upi

3-entrar-NOML 3 formiga POSs-buraco c-em

"Não dava para passar (não cabia) pelo buraco do formigueiro" 
57) A'e re uzeapo tahywai xixirogaturumu, na'e zekaipo uixe oho a'e tahywai ikwaw rupi kury.

a. a'e re u-ze-apo t-ahyw-ai

3 depois 3-REFL-fazer G-formiga-DIM

b. $\quad$ xixiro-gatu-r-umu

várias.espécies.diferentes-C-TRANSL

c. na'e ze-k(wehe)-aipo u-ixe o-ho a'e

então N.AT-faz.tempo-dúvida 3 -entrar 3 -ir $\quad$ ele

d. t-ahyw-ai i-kwaw r-upi kury

G-formiga-dim Poss-buraco c-por CHNG

"Depois, ele se transformou em formigas de vários tamanhos, até que conseguiu passar pelo buraco do formigueiro"

58) Aze ze-k(wehe)-aipo uixe oho uhem zeiakpo amo taw pe.

a. aze ze-k(wehe)-aipo w-ixe o-ho u-hem

se $\quad$ N.AT-faz.tempo-dúvida 3-entrar 3-ir 3-chegar

b. ze-k(wehe)-aipo amo taw ø-pe

N.AT-faz.tempo-dúvida outro aldeia C-em

"Passando pelo buraco, ele chegou a uma aldeia"

59) A'e pe ukàzikàzim zekaipo iko a'e pehar wanuwi.

a. a'e pe u-kàzi-kàzim ze-k(wehe)-aipo

3 em 3-esconder-RED N.AT-faz.tempo-dúvida

b. iko a'e ø-pe-har wa=n-uwi

estar ele C-em-NOML $3 \mathrm{PL}=\mathrm{C}$-de

"Lá, ele (o irmão mais velho) passou vários dias escondido deles (dos seres sobrenaturais)"

60) Ma'ema'e xixigaturumu zekaipo zeapo iko a'e pe wanuwi.

a. ma'e-ma'e xixiro-gatu-r-umu ze-k(wehe)-aipo

coisa-coisa várias.espécies.diferentes-C-TRANSL N.AT-faz.tempo-dúvida

b. ze-apo iko a'e pe wa=n-uwi

REFL-fazer ser 3 em $3 \mathrm{PL}=\mathrm{C}-\mathrm{de}$

"Ele (o irmão mais velho) se transformava em vários insetos e animais

para se esconder deles (dos cachorros do céu)" 
61) A'epe uiko mehe uwexak pawkatu a'e zemara'itaw iko a'e pe.

a. a'e pe u-iko mehe u-wexak paw katu a'e 3 em 3-ser quando 3-ver tudo ENF ele

b. zemara'i-taw i-ko a'e ø-pe brincar-NOML 3-ser $3 \quad$ C-em

"Então, ele pôde observar as festas e os rituais"

62) A'e pe uwexak zekaipo amo mainumy we zepe tentehar tua'u zepe zekaipo ra`a

a. a'e pe u-wexak zekaipo amo mainumy

3 em 3-ver N.AT-faz.tempo-dúvida outro beija.flor

b. we zepe Tentehar t-ua'u

ainda contrário.ao.fato Tenetehára G-ancião

c. zepe zekaipo ra'a

contrário.ao.fato N.AT-faz.tempo-dúvida DUB

"Lá, ele encontrou um ancião que estava em forma de beija-flor"

63) Upuranu tua'u hehe:

u-puranu t-ua'u h-ehe

3-perguntar G-ancião NC-em

"O ancião perguntou a ele"

64) -Ma'e tuwe erezapo ikoxe ty, i’i izupe?

ma'e tuwe ere-zapo iko-xe ty i-'i i-zupe

QU ENF 2sG-fazer estar-aqui GNDL 3-fazer NC-em

"O que você está fazendo aqui?"

65) A'e Tentehar tyky'yr maizu umume'u parupi ma'e uzeapo ma'e izupe.

a. a'e Tentehar t-yky'yr Maizu

3 Tenetehára G-irmão.mais.velho Maizu

b. u-mume'u pa(w)-r-upi

3-contar tudo-C-em

c. ma'e u-ze-apo-ma'e i-zupe

coisa 3-REFL-fazer-NOML NC-para

"O irmão mais velho Maizu contou tudo o que ocorrido para ele (o ancião)" 
66) Na'e a'e mainumy uzeapo tentehar rumu izupe kury, uwexakar tywyr hemi'iwà kwer izupe no.

a. na'e a'e Mainumy u-ze-apo Tentehar então 1 Mainumy 3-REFL-fazer Tenetehára

b. r-umu i-zupe kury u-wexak-(k)ar t-ywyr

3-TRANSL NC-em CHNG 3-ver-CAUS G-irmão.mais.novo

c. h-emi-'iwà-kwer i-zupe no

3-NOML-flechar-PASS C-para MNT

"O ancião se transformou em um ser humano e levou o irmão mais velho para aquele que foi flechado (o ferido (um dos cachorros do céu))"

67) Uhem oho a'e zawar iziwà pyrer tupaw pe wà kury, teko romo zekaipo uwuz kury, i’i maizu pe, hekatu tànà'àg kury ty i’i izupe.

a. u-hem o-ho a'e zawar i-ziwà

3-chegar 3-ir 3 cachorro 3-flechar

b. pyr-(kw)er tupaw ø-pe wà kury

NOML-PASS lugar.de.estar.deitado C-em PL CHNG

c. teko r-omo ze-k(wehe)-aipo

gente C-TRANSL N.AT-faz.tempo-dúvida

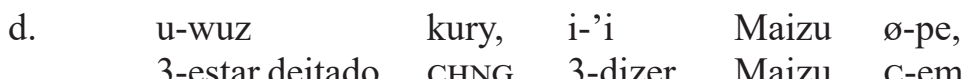

e. he-katu tànà'àg kury ty i-'i i-zupe 1-bom sentado CHNG GNDL 3-DIZER NC-para

"Chegando ao lugar onde o cachorro ferido estava deitado, que agora já havia se transformado em pessoa, (o ancião) disse ao Maizu que ele (o cachorro) estava bem (e assentado)"

68) A'e teko iziwà'arer, iziwàziwà zekaipo wereko taw mitepe wà

a. a'e teko i-ziwà-' (h)ar-(kw)er i-ziwà-ziwà

3 gente 3-flechar-NOM-PASS 3-flechar-RED

b. ze-k(wehe)-aipo w-ere-(e)ko-taw myter ø-pe wà N.AT-faz.tempo-dúvida 3-COM-estar-aldeia meio C-em PL "A pessoa que o havia flechado estava, por eles, sendo flechada no centro da aldeia" 
69) Na'e a'e tua'u Mair uhapukaz izupe uwexakar a'e teko iziwàziwà pyr izupe.

a. na'e a'e t-ua'u Mair u-hapukaz i-zupe então 3 GEN-ancião Mair 3-gritar NC-para

b. u-wexa-kar a'e teko i-ziwàziwà-pyr i-zupe 3-ver-CAUs 3 gente 3-castigar-NOML NC-para "Então, o ancião chamou (o irmão mais velho, Maira) para ver a pessoa que estava sendo castigada"

70) Uhem oho a'e pe wà kury, tua'u i'i tyky'yr pe eziwà neno ty i'i izupe

a. u-hem o-ho a'e pe wà kury

3-chegar 3-ir 3 em PL CHNG

b. t-ua'u i-’i t-yky'yr ø-pe

G-ancião 3-dizer G-irmão.mais.velho c-em

c. e-ziwà ne no ty i-'i i-zupe 2IMP-flechar você MNT GNDL 3-dizer NC-em "Chegando lá, o ancião disse para o irmão mais velho dar uma flechada nele (no irmão mais novo) também”

71) Mair i'i izupe : -Heta hepuneraw purumukatu haw ihe ty i'i' izupe.

a. Mair i-'i i-zupe h-eta h-epuner-(h)aw

Mair 3-dizer NC-para 3-ter 3-poder-NOML

b. puru-mu-katu-haw ihe ty i-'i i-zupe gente-CAUS-bom-NOML 1SG GNDL 3-dizer 3-dizer "O Mair disse a ele (ao ancião): 'Eu possuo poderes para curar"”

72) Na'e Maizu iziwà uiwyry hetekwer ikwapar'ymaz.

a. na’e Maizu i-zywà u-iwyry h-etekwer então Maizu 3-flechar irmão.mais.novo 3-corpo

b. i-kwa(w)-par 'ymaz

3-conhecer-NOML NEG

"Então, ele (o irmão mais velho) flechou o corpo do próprio irmão fingindo que não o conhecia"

73) A'e re waraha zekaipo imugweraw pà wà.

a. a'e re w-ara-ha ze-k(wehe)-aipo

3 depois 3-COM-ir N.AT-faz.tempo-dúvida 
b. i-mu-gwer-(h)aw pà wà

3-CAUS-ressuscitar-NOML GER PL

"Depois disso, o levaram (o irmão mais novo) para um ritual que o ressuscitaria"

74) Umugweraw kwarer zekaipo Mair a’e.

u-mu-gweraw kwarer ze-k(wehe)-aipo Mair a'e

3-CAUS-ressuscitar menino N.AT-faz.tempo-dúvida Mair ele

"Então, o Mair o ressuscitou (o irmão mais velho ressuscitou o irmão mais novo)"

75) Tywyr Maira'i, nukwaw kwaw ma'e izapo ma'e a'e, na'e uzewyry oho wekohaw pe wà kury.

a. $\quad$-ywyr $\quad$ Maira'i, n-u-kwaw-kwaw

3.irmão.novo Maira'i NEG-3-saber-NEG

b. ma'e i-zapo-ma'e a'e

coisa 3-fazer-NOML 3

c. na'e u-zewyr o-ho w-eko-haw ø-pe wà kury então 3-voltar 3-ir CORR-estar-NOML C-para PL CHNG "O irmão mais novo, Maira'i, sem saber de nada do que havia sido feito, voltou para sua (própria) aldeia"

76) Akwez zemaraitaw a'e pe hemixakwer uwerur ko zane rekohaw pe, parupi katu ma'e wemixakwer;

a. akwez zemaraz-taw a'e pe h-emi-(e)xak-(k)wer

aquele brincar-NOML 3 em 3-NOML-ver-PASS

b. u-weru-(u)r ko zane $_{\text {INCL }}=$ r-eko-haw ø-pe,

3-COM-vir aqui $1 \mathrm{PL}=\mathrm{C}$-ser-NOML $\quad \mathrm{C}-\mathrm{em}$

c. pa(w) r-upi katu ma'e w-emi-(e)xak-(k)wer

tudo C-em ENF coisa 3-NOML-ver-PASS

"Os rituais que ele (o irmão mais novo) aprendeu e viu lá ele trouxe para cá, no nosso mundo"

77) Wyra'ohaw, kokumu wakwaztaw, wàhuhaw, kwàtàzgwerai wawira'ohaw, upuwipuwir kwer wazimuàir haw, paze ma'e waze'agaw paw haw, zegaraiwpaw

a. w-yr(a)-'o-haw

3-gavião-plumagem-NOML 
$\begin{array}{lll}\text { b. } & \text { kokumu } & \text { wa-kwaz-taw } \\ \text { jovem } & \text { PL-mandar-NOML }\end{array}$

c. wà-(u)hu-haw

PL-AUM-NOML

d. kwàtàz-gwer-ai wa-wir(a)-'o-haw

criança-PL-DIM PL-criar-carne-NOML

e. u-puwi-puwir-kwer wa-zimuàir haw

3-largar-largar-PASS PL- adoçar.se NOML

f. paze ma'e wa-ze'aga(w)-paw haw

pajé coisa PL-testar-NOM-todo lugar

g. zegar-aiw-paw

cantar-ruim-NOML

"A Festa da menina-moça, a festa dos rapazes, a festa da colheita, a festa das criancinhas, a festa dos separados (divorciados), a festa dos pajés e as orações Tenetehára"

Literalmente: [o evento da plumagem do gavião (a menina), o evento do mandado ao jovem, o evento de ter algo em abundância, o evento do crescimento das crianças, o evento do adoçamento daqueles que se largam (separaram-se), o evento de os pajés se testarem, o evento da cantoria (contra) das coisas ruins]

78) Hàiràgaw rehe hàg'py zekaipo uzemu'e, akwez pe.

a. hàir rà'à -gaw hàg'py

mel 3-imitar-NOML C-em primeiro

b. ze-k(wehe)-aipo u-ze-mu-'e akwez pe

N.AT-faz.tempo-dúvida 3-REFL-CAUS-expressar aquele lá

"A festa do mel (imitador de mel) foi a primeira festa que ele aprendeu lá"

79) Ma'e imume'u haw izepymehe akwez zawar wazewenugar wà, Hàir ma'eputyr rehe arer zekaipo umui'e wàiko wà, a'e hàiràgaw pàràm a'e.

a. ma'e i-mume'u-haw i-zepymehe akwez zawar

coisa 3-contar-NOML 3-começo.quando aquele cachorro 
b. wa-ze-w-enu-gar wà

PL-REFL-3-parecer-NOM PL

c. hàir ma'eputyr r-ehe (h)a(r)-(kw)rer ze-k(wehe)-aipo

mel flor C-em NOML-PASS N.AT-faz.tempo-dúvida

d. u-mu-i’e wà-iko wà

3-CAUS-expremer PL-ser PL

e. a'e h-àirà-gaw ø-pà-(ha)r-àm a'e

3 3-imitar-NOML C-em-NOML-FUT 3

"No início da história (contação da coisa), os seres que pareciam com cachorros estavam espremendo o néctar das flores para a festa do mel"

80) Nàzewe zekaipo zane zegar heta wàm, na'aw imume'u haw ipehegwer xe.

a. nàzewe ze-k(wehe)-aipo zane zegar h-eta (ha)w-(r)àm N.AT-faz.tempo-dúvida $\quad 1 \mathrm{PL}_{\mathrm{INCL}}$ cantar 3-ter NOML-FUT

b. na'aw i-mume'u haw i-pehegwer xe aqui.está 3-história NOML 3-parte GNDL

"Assim, surgiram nossas cantorias e aqui está uma parte da história"

\section{Figura 1 - Instrumento utilizado antigamente durante as festas}

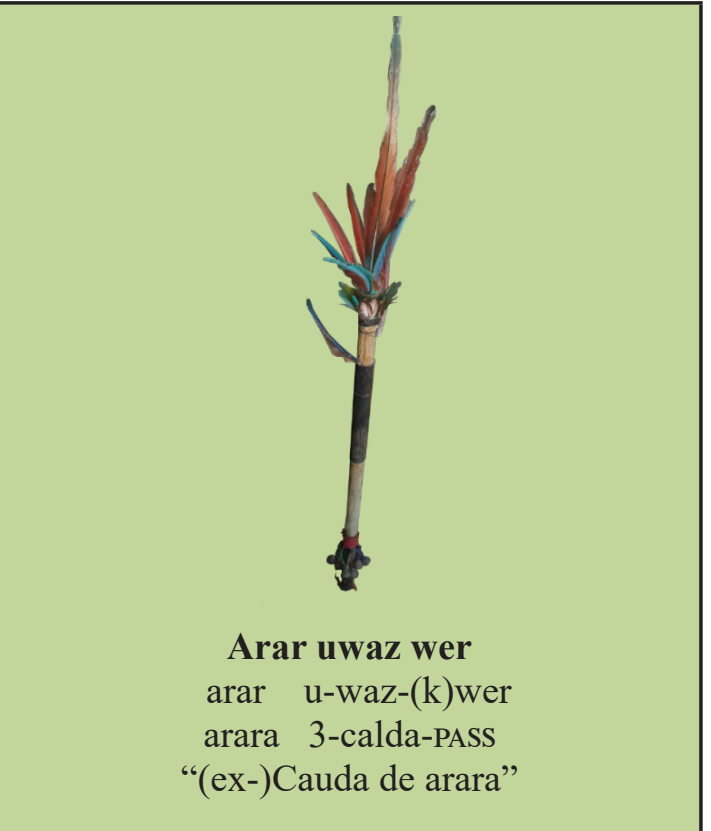

Fonte: foto de Luciana Almeida de Oliveira 
Após a reprodução e análise morfológica dessa importante história original, passamos às nossas palavras finais.

\section{Palavras Finais}

Neste artigo, foi apresentado um panorama sucinto acerca da literatura indígena durante o Romantismo no Brasil. Defendemos a tese de que as contradições desse período foram inevitáveis, constituindo-se apenas de idiossincrasias daquele momento literário. Mais especificamente, sustentamos que, naquele contexto, a voz do indígena brasileiro não se expressaria de outra forma senão por meio da ilegitimidade de sua voz enviesada pela voz do colonizador europeu que atribuía ao indígena sua visão de mundo preconcebida.

Outro objetivo deste texto foi evidenciar um paradoxo hodierno inevitável a respeito da relação que se estabelece entre língua, sistemas linguísticos acadêmicos, literatura e internet. Nessa linha de investigação, apesar de os espaços digitais e os sistemas metalinguísticos acadêmicos de documentação e divulgação das histórias originárias serem alheios à cultura indígena, a coleta e a disponibilização digital de narrativas nos cibercaminhos podem ter como corolário a contribuição com a preservação, documentação e revitalização linguística e literária das culturas indígenas. Diante disso, foram reproduzidas e apresentadas a análise morfológica da história Tenetehára Izipy mehe Tentehar wazegar haw herur awer (No início, quando os Teneteháras trouxeram a cantoria.

Esta história descreve como foram criadas as festas tradicionais do povo Tenetehára. A festa da menina moça, a festa dos rapazes, a festa da colheita, a festa das criancinhas, a festa dos separados, a festa dos pajés e as orações Tenetehára. Segundo esta história originária, essas festas foram trazidas por um antigo Tenetehára que fora levado a outro mundo por seres do céu. Assim, ao voltar para sua própria casa, ele transmite aos seus parentes os rituais aprendidos e apreendidos no outro mundo.

\section{Referências}

Brasil. 1988. Constituição da República Federativa do Brasil de 1988. Brasília, Disponível em: <http://www.planalto.gov.br/ccivil_03/constituicao/constituicao. htm>. Acesso em 24 abril 2020.

Bruno, Marilda Moraes Garcia and Ilma Regina Castro Saramago Souza. 2016. Oralidade e Escrita: Contrapontos da Palavra Guarani. Revista (Con) Textos linguísticos, 10, 111-124.

Camargos, Quesler Fagundes. 2017. Aplicativização, causativização e nominalização: uma análise unificada de estruturas argumentais em Tenetehára-Guajajára (Família Tupí-Guaraní). Doutorado em Linguística, Universidade Federal de Minas Gerais.

Caminha, Pero Vaz de. 1968. Carta a El Rey Dom Manuel. Rio de Janeiro: Sabiá. 
Candido, A.. 2000. A educação pela noite \& outros ensaios. São Paulo: Editora Ática.

Celeste, Jennifer da Silva Gramiani and Juliana Gervason Defilippo. 2017. Pedro Antônio Gabriel e a poesia em desvio: cibercaminhos. Anais do XII Jogo do Livro e II Seminário Latino-Americano: Palavras em Deriva. Belo Horizonte: UFMG, 1-8.

Castro, Ricardo Campos. 2017. Morfossintaxe Tenetehára (Tupi-Guaraní). Doutorado em Linguística, Universidade Federal de Minas Gerais.

Castro, Ricardo Campos. 2018. A tradição literária brasileira e a voz indígena. In, Ana Paula Teixeira Porto, Cilene Margarete Pereira and Juliana Gervason Defilippo (org.), Leituras da literatura brasileira atual (1990-2018), 1. Rio de Janeiro: Multifoco, 231-252.

Castro, Ricardo Campos and Pilar Chamorro Fernandez. 2019. From brazilian literary tradition to cyberpaths: The voice of indigenous peoples. Revista Verbo de Minas, 20(35), 67-83.

Dalcastagne, Regina. 2013. Deslocamentos de gênero na narrativa brasileira contemporânea. São Paulo: Horizonte.

Duarte, Fábio B.. 2007. Estudos de morfossintaxe Tenetehára. Belo Horizonte: UFMG.

Duarte, Fábio B.. 2016. Diversidade Linguística no Brasil: a situação das línguas ameríndias. Revista Caletroscópio, 4, 27-62.

Duarte, Fábio Bonfim Duarte and Quesler Fagundes Camargos, Ricardo Campos Castro, Cíntia Maria Santana Silva, Marina da Silva Guajajara. 2018 Coletânea de narrativas Guajajára. Belo Horizonte: Faculdade de Letras (FALE) da Universidade Federal de Minas Gerais.

Dietrich, Wolf. 2020. Tiempo, aspecto y evidencialidad em guaraní. LIAMES: Línguas Indigenas americanas, 10, 67-83.

Soares, Marília Facó and Fernando Orphão de Carvalho. 2014. As hipóteses de Aryon Rodrigues: validade, valor e papel no cenário dos estudos de línguas indígenas e de linguística histórica. D.E.L.T.A., 30(3), 543-570.

Guesse, Érika Bergamasco. 2013. Prática escritural indígena: língua e literatura fortalecendo a identidade e a cultura. Anais do SILEL, 3, EDUFU, 01-08.

Guesse, Érika Bergamasco. 2013. Da oralidade à escrita: os mitos e a literatura indígena no Brasil. Anais do SILEL, 2, EDUFU, 01-11.

Giles, D. 2010. Psychology of the media. New York: Palgrace Macmillan.

Jobim, José Luís. 1997/1998. Indianismo literário na cultura do romantismo. Revista de Letras, 37/38, 35-48.

Minápoty, L.. 2011. Com a noite veio o sono. São Paulo: Texto Editora LTDA/Grupo Leya.

Munduruku, Daniel. (s.d.). A escrita e a autoria fortalecendo a identidade. Available in $\quad<\mathrm{http}$ ://pib.socioambiental.org/pt/c/iniciativas-indigenas/autoria-indigena/aescrita-e-aautoria-fortalecendo-a-identidade $>$.

Pagnan, Celso Leopoldo. 2005. Alencar e Machado: leituras e indianismo. Terra roxa e outras terras. Revista de Estudos Literários, 6, 72-85. 
Resende, Beatriz. 2008. Contemporâneos: expressões da literatura brasileira no século XXI. Rio de Janeiro: Editora Casa da Palavra/Biblioteca Nacional.

Rodrigues, Aryon Dall'Igna and Ana Suelly Arruda Câmara Cabral. Revendo a classificação da família Tupí-Guaraní. In Ana Suelly Cabral and Aryon Rodrigues (orgs). Línguas Indígenas Brasileiras: Fonologia, Gramática e História. Atas do I Encontro Internacional do Grupo de Trabalho sobre Línguas Indígenas da ANPOLL. Belém: Editora UFPA.

Rodrigues, Aryon Dall'Igna. 1984/1985. Relações Internas na família lingüística TupíGuaraní. Revista de Antropologia, 19, 33-35.

Rodrigues, Aryon Dall'Igna. 1992. Um marcador Macro-Jê de posse alienável. Anais da $44^{\circ}$ Reunião da SBPC.

Rodrigues, Aryon Dall’Igna. 1955. As "línguas impuras” da família Tupí-Guaraní. Anais do XXXI Congresso Internacional de Americanistas, São Paulo, 1055-1071.

Santos, Célia Regina dos and Vera Helena Gomes Wielewicki. Literatura de autoria de minorias étnicas e sexuais. In Thomas Bonnici and Lúcia Osana Zolin (orgs.). Teoria literária: abordagens históricas e tendências contemporâneas. Maringá: Eduem.

Schøllhammer, K. E. 2009. Ficção brasileira contemporânea, 1. Rio de Janeiro: Civilização Brasileira.

Souza, Lynn Mario Menezes de. 2001. De estória à história: a escrita indígena no Brasil. Revista da Biblioteca Mário de Andrade, 59, 69-72. 